\title{
Effect of Contact Time on the Level of Phthalates in Polyethylene Terephthalate-bottled Water from the Point of Sale
}

\author{
Abdul Rasid Hazira', ${ }^{1,2}$ Ungku Zainal Abidin Ungku Fatimah ${ }^{3,4}$, Selamat Jinap ${ }^{1,5}$, \\ Syaliza Omar ${ }^{6}$ and Maimunah Sanny ${ }^{1,5^{*}}$ \\ ${ }^{1}$ Department of Food Science, Faculty of Food Science and Technology, Universiti Putra Malaysia, 43400 \\ UPM Serdang, Selangor, Malaysia \\ ${ }^{2}$ Food Section, Public Health Laboratory Kota Kinabalu, Ministry of Health Malaysia, 88850 Kota Kinabalu, \\ Sabah, Malaysia \\ ${ }^{3}$ Department of Food Service and Management, Faculty of Food Science and Technology, Universiti Putra \\ Malaysia, 43400 UPM Serdang, Selangor, Malaysia \\ ${ }^{4}$ Halal Products Research Institute, Universiti Putra Malaysia, 43400 UPM Serdang, Selangor, Malaysia \\ ${ }^{5}$ Laboratory of Food Safety and Food Integrity, Institute of Tropical Agriculture and Food Security, \\ Universiti Putra Malaysia, 43400 UPM, Serdang, Selangor, Malaysia \\ ${ }^{6}$ Faculty of Pharmacy, Universiti Sultan Zainal Abidin, Besut Campus, 222000, Besut,Terengganu, Malaysia
}

\section{ABSTRACT}

The study aimed to evaluate the effect of contact time on the level of phthalates in polyethylene terephthalate (PET)-bottled water commercially available on the market. Different water types (drinking water, mineral water, and sparkling water) in PET bottles and mineral water in glass bottles were collected. Control (before bottling) and freshly produced (0-month) samples were collected at manufacturing sites. In contrast, samples at 6, 12, and 18 months of contact times were collected randomly from hypermarkets and supermarkets in Klang Valley, Malaysia. The samples were analyzed using LC-MS/MS with deuterated

ARTICLE INFO

Article history:

Received: 10 January 2021

Accepted: 18 February 2021

Published: 28 May 2021

DOI: https://doi.org/10.47836/pjtas.44.2.08

E-mail addresses:

xeerarasid@gmail.com (Abdul Rasid Hazira)

ungkufatimah@upm.edu.my (Ungku Zainal Abidin Ungku Fatimah)

sjinap@gmail.com (Selamat Jinap)

dr.syaliza@gmail.com (Syaliza Omar)

s_maimunah@upm.edu.my (Maimunah Sanny)

*Corresponding author
DEHP as the internal standard. DEHP, DMP, DEP, DnOP, and BBP were not detected in drinking, mineral, and sparkling water in both PET and glass bottles. However, DBP was detected within the range of 0.68 to 1.11 $\mathrm{ng} / \mathrm{mL}$ for mineral water and 0.55 to $0.59 \mathrm{ng} /$ $\mathrm{mL}$ for drinking water in PET bottles. All types of phthalates, including DBP, were not detected in the control and 0-month samples. DBP was detected at $0.59 \mathrm{ng} / \mathrm{mL}$ at 6 months of contact time and $0.55 \mathrm{ng} / \mathrm{mL}$ at 12 months 
of contact time in PET-bottled drinking water samples; the difference, however, was not significant. It appears that contact time did not significantly affect DBP levels.

Keywords: Contact time, LC-MS/MS, PET-bottled water, phthalates, point of sale

\section{INTRODUCTION}

The popularity of bottled water is rising nowadays in every part of the world with the increased usage of bottled water widely due to its convenience, inexpensive cost, and hygienic nature (Gleick, 2010). There is a rapid increase in the usage of polyethylene terephthalate (PET) bottles to package bottled water and phthalates - a type of plasticizer that is widely used in the plastic-making process (Robertson, 2013). Plasticizers are chemical additives added to polymeric products to provide durability, elasticity, and flexibility (Jia et al., 2018). Phthalates are available in free form and not chemically bound in plastic. As a result, they can potentially migrate from packaging materials into our food and beverages and cause contamination during production and storage (Gomez-Hens \& AguilarCaballos, 2003). The compound has become a health concern due to its endocrine disrupting properties (LaFleur \& Schug, 2011). Among all phthalate esters, only diethylhexyl phthalate (DEHP) is classified as a $2 \mathrm{~B}$ substance and considered as possibly carcinogenic to humans (International Agency for Research on Cancer [IARC], 1982; Ito et al., 2019). In order to protect human health, the European Food Safety Authority established a total daily intake (TDI) for some of these pollutants; in particular, $0.05 \mathrm{mg} / \mathrm{kg} / \mathrm{bw} /$ day for DEHP, $0.01 \mathrm{mg} / \mathrm{kg} / \mathrm{bw} /$ day for dibutyl phthalate (DBP), and $0.5 \mathrm{mg} / \mathrm{kg} / \mathrm{bw} /$ day for benzyl butyl phthalate (BBP) (Silano et al., 2019).

Several researchers have reported the occurrence of phthalates in bottled water. High levels of DEHP in the range of $350 \mu \mathrm{g} / \mathrm{kg}-8.78 \mathrm{mg} / \mathrm{kg}$ were detected in bottled water in PET (Al-Saleh et al., 2011; Amiridou \& Voutsa, 2011; Bosnir et al., 2007). Other researchers (Amiridou \& Voutsa, 2011; Penalver et al., 2001) detected DBP in bottled water in the range of 0.1-44 ng/mL, whereas Montuori et al. (2008), as well as Al-Saleh et al. (2011), detected BBP in the range of $0.33-9.45 \mathrm{ng} / \mathrm{mL}$. Different authors detected diethyl phthalate (DEP) in bottled water in the range of 1.536-33 ng/mL (Al-Saleh et al., 2011; Amiridou \& Voutsa, 2011). Chang et al. (2015) detected di-n-octyl phthalate (DnOP) in disposable drinking water cups at $18.1 \mathrm{ng} /$ $\mathrm{mL}$. Fellow researchers in Malaysia, e.g., Chong et al. (2011) determined phthalates in polypropylene consumer products (such as food containers, instant noodle cups, and snack containers) and found the examined samples to contain DEHP ranging from $830 \mathrm{mg} / \mathrm{kg}$ to $1270 \mathrm{mg} / \mathrm{kg}$. Ibrahim et al. (2014) determined phthalates in different palm oil brands, which were packed in PET bottles in the retail market in Malaysia. They detected DBP and BBP at concentrations less than $1 \mathrm{mg} / \mathrm{kg}$. To our knowledge, there are no studies done in Malaysia on the 
level of phthalates in bottled water that is commercially available on the market.

Different authors reported that the occurrence of phthalates depends strongly on the $\mathrm{pH}$ (carbonated vs. non-carbonated samples) (Bosnir et al., 2007; Keresztes et al., 2013; Montuori et al., 2008), storage time, storage temperature, and exposure to sunlight (Leivadara et al., 2008; Schmid et al., 2008). In addition to mineral water considered a non-carbonated drink, carbonated drinks such as soft drinks and sparkling water are also bottled using PET. Keresztes et al. (2013) reported that DBP, BBP, and DEHP were detected in noncarbonated drinks but not in carbonated mineral water samples. Besides PET, glass is also used to pack mineral water. Montuori et al. (2008) reported that the concentrations of phthalates were nearly 20 times higher in mineral water samples in PET bottles than those from glass bottles, with total levels of phthalates being at 3.52 and $0.19 \mathrm{ng} / \mathrm{mL}$, respectively. Further, different researchers stated that aging and plastic packaging breakdown might accelerate the migration process (Amiridou \& Voutsa, 2011; Rahman \& Brazel, 2004). Keresztes et al. (2013) reported that DEHP could be detected after 44 days of storage at $22^{\circ} \mathrm{C}$, and its leaching was most pronounced when samples were stored for over 1200 days.

To the best of our knowledge, no study has reported the effect of contact time on the level of phthalates in PET-bottled water in Malaysia. Therefore, the present study was conducted to determine the effect of contact time on the level of phthalates, specifically
DEHP, dimethyl phthalate (DMP), DEP, DnOP, DBP, and BBP in PET-bottled water that is commercially available on the market. Different types of water, i.e., drinking water, mineral water, and sparkling water in PET bottles and mineral water in glass bottles, were collected. Control (before bottling) and freshly produced (0-month) samples were collected at manufacturing sites, whereas samples at 6,12 , and 18 months of contact times were collected randomly from hypermarkets and supermarkets in Klang Valley, Malaysia. The samples were analyzed using LC-MS/MS, and deuterated DEHP was used as the internal standard.

\section{MATERIALS AND METHODS}

\section{Characteristic of Samples}

Fifty-four samples of bottled water were collected. Different types of water, i.e., drinking water, mineral water, and sparkling water in PET bottles and mineral water in glass bottles, were collected. Three different drinking water and mineral water brands in PET bottles were collected, whereas one brand of sparkling water in PET bottles and mineral water in glass bottles was collected. Samples manufactured by the following companies were collected: mineral water, drinking water, and sparkling water in PET bottles by Company A; mineral water in PET bottles by Company B and C; drinking water in PET bottles by Company $\mathrm{D}$ and $\mathrm{E}$; and mineral water in glass bottles manufactured by Company F. In terms of size, PET-bottled water collected from Company A was in $600 \mathrm{~mL}$ containers, whereas PET-bottled water from other 
companies was in $500 \mathrm{~mL}$ containers. Glassbottled water from company $\mathrm{F}$ was in 1000 $\mathrm{mL}$ containers. Company $\mathrm{A}$ is located in Perak, Malaysia; Company B is located in Kedah, Malaysia; Company C, D, and E are located in Selangor, Malaysia; and company $\mathrm{F}$ is located in France.

In the present study, bottled water's shelf life was used to select the samples as this type of information is usually printed on the packaging. Typically, the shelf life of commercially bottled water is 24 months. However, some companies have products with a shelf life of 36 months. Control (before bottling) and freshly produced (0-month of contact time) samples were collected at manufacturing sites. Bottled water samples of other contact times, i.e., 6 , 12 , and 18 months, were collected randomly from hypermarkets and supermarkets in Klang Valley, Malaysia. Contact time was calculated based on the expiry date. One batch of control samples and two different batches of $0,6,12$, and 18-months bottled samples were collected. All samples were kept sealed in their original packaging. They were stored in a refrigerator for no longer than a week before the time of analysis. Control samples were taken directly from the pipeline (before bottling) of manufacturing sites, using $500 \mathrm{~mL}$ glass bottles.

\section{Phthalates Analysis}

Chemicals and Stock Solutions. A high purity analytical grade of methanol was purchased from Sigma-Aldrich Chemicals (St. Louis, USA). EPA 606-M Phthalate
Esters Mix (DMP, DEP, DEHP, DnOP, DBP, and BBP) with a $200 \mathrm{mg} / \mathrm{mL}$ concentration was purchased from Supelco. Deuterated phthalate (DEHP-d4), which was used as the internal standard throughout the study, was purchased from Dr. Ehrenstorfer GmbH, Germany.

A stock solution of Phthalate Esters Mix $(1 \mathrm{mg} / \mathrm{mL})$ and DEHP-d4 (100 mg/mL) was prepared by dissolving the compound in methanol. The stock solution of Phthalate Esters Mix was further diluted to prepare intermediate standard to concentrations of $50 \mathrm{ng} / \mathrm{mL}$ and $100 \mathrm{ng} / \mathrm{mL}$ with methanol. Similarly, the stock solution of DEHP-d4 was further diluted to prepare a working standard to concentrations of $1 \mathrm{mg} / \mathrm{mL}$ with methanol. All stock solutions and intermediate standards were stored in a refrigerator at $4{ }^{\circ} \mathrm{C}$ for a maximum of 1 year.

Sample Preparation. The procedure described by Schreiber et al. (2011) was followed. A $1 \mathrm{~mL}$ water sample was accurately transferred to a $10 \mathrm{~mL}$ volumetric flask and made up with methanol. A $100 \mathrm{ml}$ of $100 \mathrm{ng} / \mathrm{mL}$ internal standard (DEHP-d4) was added to the mixture and shaken well. The mixture was then allowed to stand for 10 minutes before being transferred into a vial for LC-MS-MS analysis.

LC-MS/MS Analysis. The detection of phthalates in bottled water was performed on PerkinElmer Flexar UHPLC AS system (PerkinElmer, Waltham, Massachusetts, US) coupled with 3200 QTRAP ${ }^{\circledR}$ Linear Ion Trap Quadrupole LC-MS/MS operated in 
multiple reaction monitoring (MRM) mode (AB Sciex, Framingham, Massachusetts, USA). The standards contained $0.5,1,5,10$, 20, $50 \mathrm{ng} / \mathrm{mL}$ and DEHP-d4 at $10 \mathrm{ng} / \mathrm{mL}$. Twenty (20) $\mu \mathrm{L}$ was used as the injection volume.

Separation of phthalates was achieved under gradient conditions using Phenomenex Synergi Fusion-RP C18 (100 mm x 2.0 mm x $2 \mu \mathrm{m}$ ) column and fast gradient water $+0.1 \%$ formic acid and acetonitrile with $0.1 \%$ formic acid at mobile phase with a flow rate of $400 \mu \mathrm{L} / \mathrm{min}$. The following MS/MS transitions were monitored: (i) $\mathrm{m} / \mathrm{z}$ $313>205$ for BBP, (ii) 391>261 for DnOP, (iii) $195>163$ for DMP, (iv) 391 $>279$ for DEHP, (v) 223>177 for DEP, (vi) 279>205 for DBP, and (vii) 395>171 for DEHP-d4.

Quantification. The transitions of $\mathrm{m} / \mathrm{z}$ $313>205$ for BBP, 391>261 for DnOP, $195>163$ for DMP, 391>279 for DEHP, $223>177$ for DEP, $279>205$ for DBP, and $395>171$ for DEHP-d4 were used for quantification. Furthermore, m/z 313>149 for BBP, 391>149 for DnOP, 195>133 for DMP, 391>167 for DEHP, 223>149 for DEP, 279>149 for DBP, and 395>153 for DEHP-d4 were used as confirmation of peak identity. A calibration graph was constructed by plotting phthalates' peak areas relative to the internal standard against the corresponding ratios of analyte amounts. Phthalate levels in samples were calculated from the calibration slope and intercept value. The calibration curve for each phthalate esters was linear; DMP ( $\mathrm{r}=0.9958)$, DEP ( $\mathrm{r}-0.9984)$, DEHP
( $r-0.9950)$, DnOP $(r=0.9959)$, DBP $(r=0.9980)$, and BBP $(r=0.9961)$. The detection limit (LOD) was $0.5 \mathrm{ng} / \mathrm{mL}$, and recoveries were in the range of $70-120 \%$.

\section{Statistical Analysis}

All data obtained in this study were analyzed using SPSS Version 21.0 (SPSS Inc., Chicago, IL). One-way ANOVA with Tukey's test was used to determine the differences in phthalates levels among different contact times. The $p$-value of 0.05 or less was considered significant.

\section{RESULTS AND DISCUSSION}

A total of 54 bottled water samples were analyzed for phthalates at different contact times: 0, 6, 12, and 18 months with samples before bottling as the control. Table 1 shows that DEHP, DMP, DEP, DnOP, and BBP were not detected in different brands of drinking, mineral and sparkling water in PET bottles, and mineral water in glass bottles at different contact times. The findings are in agreement with Ceretti et al. (2010), who reported that DEHP was not detected in PET-bottled mineral water. Similarly, Guart et al. (2011) did not detect DEHP, DMP, or BBP in any bottled water, whether in PET or glass bottles. However, numerous authors reported high levels of phthalates in bottled water, especially DEHP (Al-Saleh et al., 2011; Amiridou \& Voutsa, 2011; Bosnir et al., 2007), DEP (Al-Saleh et al., 2011; Amiridou \& Voutsa, 2011), and BBP (Al-Saleh et al., 2011; Montuori et al., 2008). Besides, Table 1 shows that DBP was detected at $0.59 \mathrm{ng} /$ 
$\mathrm{mL}$ at 6 months of contact time and 0.55 $\mathrm{ng} / \mathrm{mL}$ at 12 months of contact time in PET-bottled drinking water samples (brand E). The difference in the means, however, was not significant. It appears that contact time did not significantly affect DBP levels. The finding seems to be in contrast with Keresztes et al. (2013), who reported that the leaching of DEHP (i.e., another type of phthalate) was the most pronounced when mineral water in PET was stored for over 1200 days at $22^{\circ} \mathrm{C}$. Keresztes et al. (2013) performed an experimental study in which researchers introduced intervention and studied the effects. However, the present study is observational in which researchers observed the effect of contact time as a risk factor without trying to influence how bottled waters are handled. To obtain insight into the actual level of phthalates in bottled water as consumed by general consumers, it is necessary to collect samples at the point of sale, in which samples were already subjected to different handling practices by different stakeholders along the supply chain. Although the drinking water samples at each contact time were collected from the same manufacturer (brand E), they are of different samples as they were gathered from different batches of production and already subjected to different handling practices along the supply chain. It might explain why the present study did not observe any significant effect of contact time on DBP levels.

In addition, DBP was detected in the range of 0.68 to $1.11 \mathrm{ng} / \mathrm{mL}$ in different brands of mineral water and 0.55 to 0.59 $\mathrm{ng} / \mathrm{mL}$ in different brands of drinking water in PET bottles. The findings agree with Serodio and Noqueira (2006) who reported that DBP was the most abundant phthalate in bottled mineral water from a Portuguese spring, with a level of 0.35 $\mathrm{ng} / \mathrm{mL}$. Moreover, all types of phthalates, including DBP, were not detected in the freshly produced ( 0 -month of contact time) and the before bottling (control) samples. It might be possible that the sources of water collected in the present study, i.e., from the states of Perak, Kedah, and Selangor, are free from phthalate contamination. Possibly, DBP that was detected at 6, 12, and 18 months was due to contamination during the bottling or handling processes. Different authors suggested that the primary sources of phthalate contamination in bottled water could be from the PVC tubes used in municipal distribution (Hahladakis et al., 2018; Sulentic et al., 2018).

DBP was detected at $0.68 \mathrm{ng} / \mathrm{mL}$ (brand A) and $1.11 \mathrm{ng} / \mathrm{mL}$ (brand C) for PETbottled mineral water at 6 months of contact time. Similarly, at $0.58 \mathrm{ng} / \mathrm{mL}$ (brand A) and $0.59 \mathrm{ng} / \mathrm{mL}$ (brand E) for PET-bottled drinking water. The difference, however, was not significant (Table 1). Furthermore, DBP was not detected in PET bottles' sparkling water (brand A) at different contact times. It appears that the type of bottled water does not significantly affect DBP levels. Sparkling water is an example of carbonated drinks, whereas mineral and drinking water that are also in PET bottles are examples of non-carbonated drinks. Different authors compared phthalate levels 
Effect of Contact Time on Phthalates

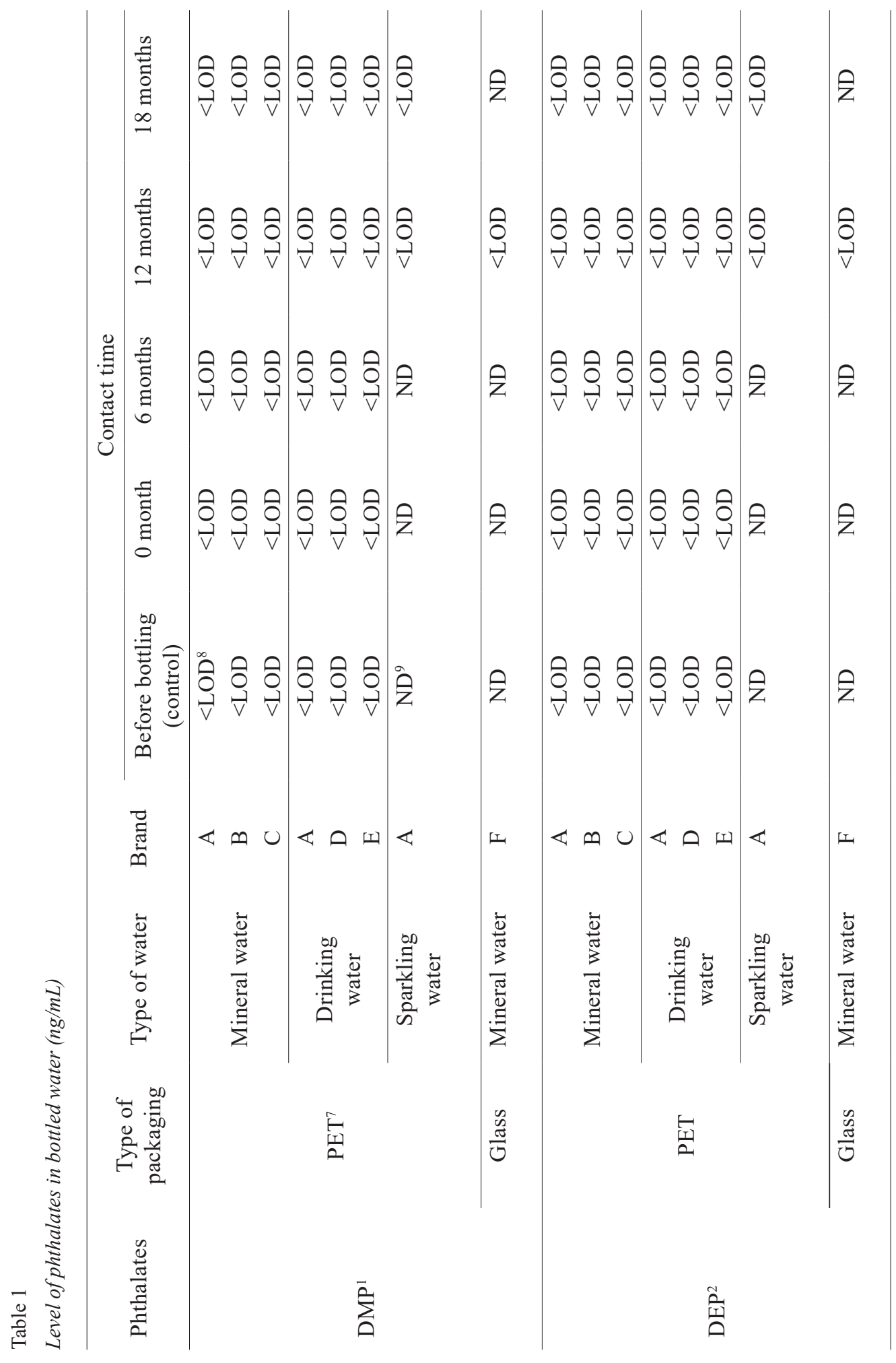

Pertanika J. Trop. Agric. Sci. 44 (2): 389 - 400 (2021) 
Abdul Rasid Hazira, Ungku Zainal Abidin Ungku Fatimah, Selamat Jinap, Syaliza Omar and Maimunah Sanny

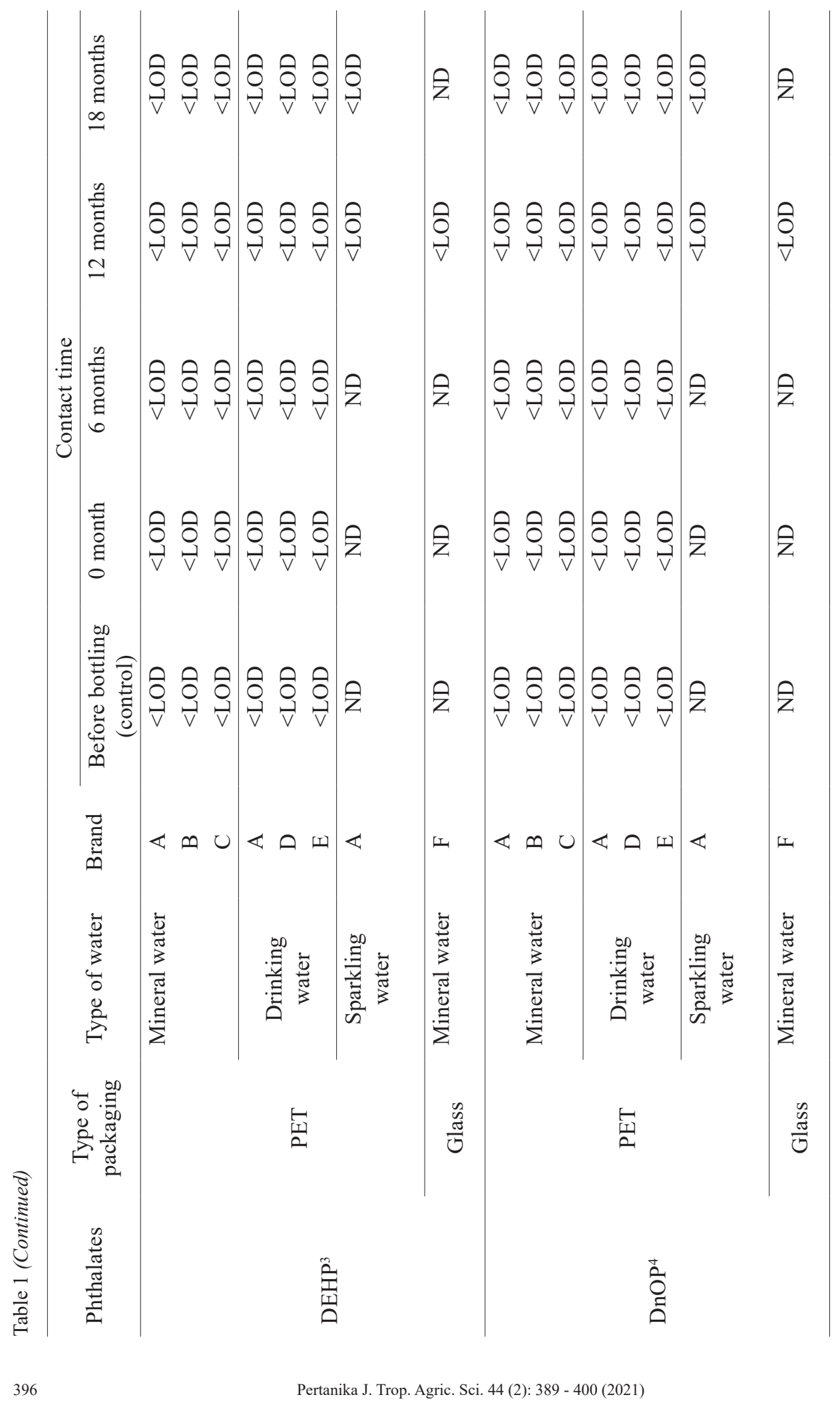




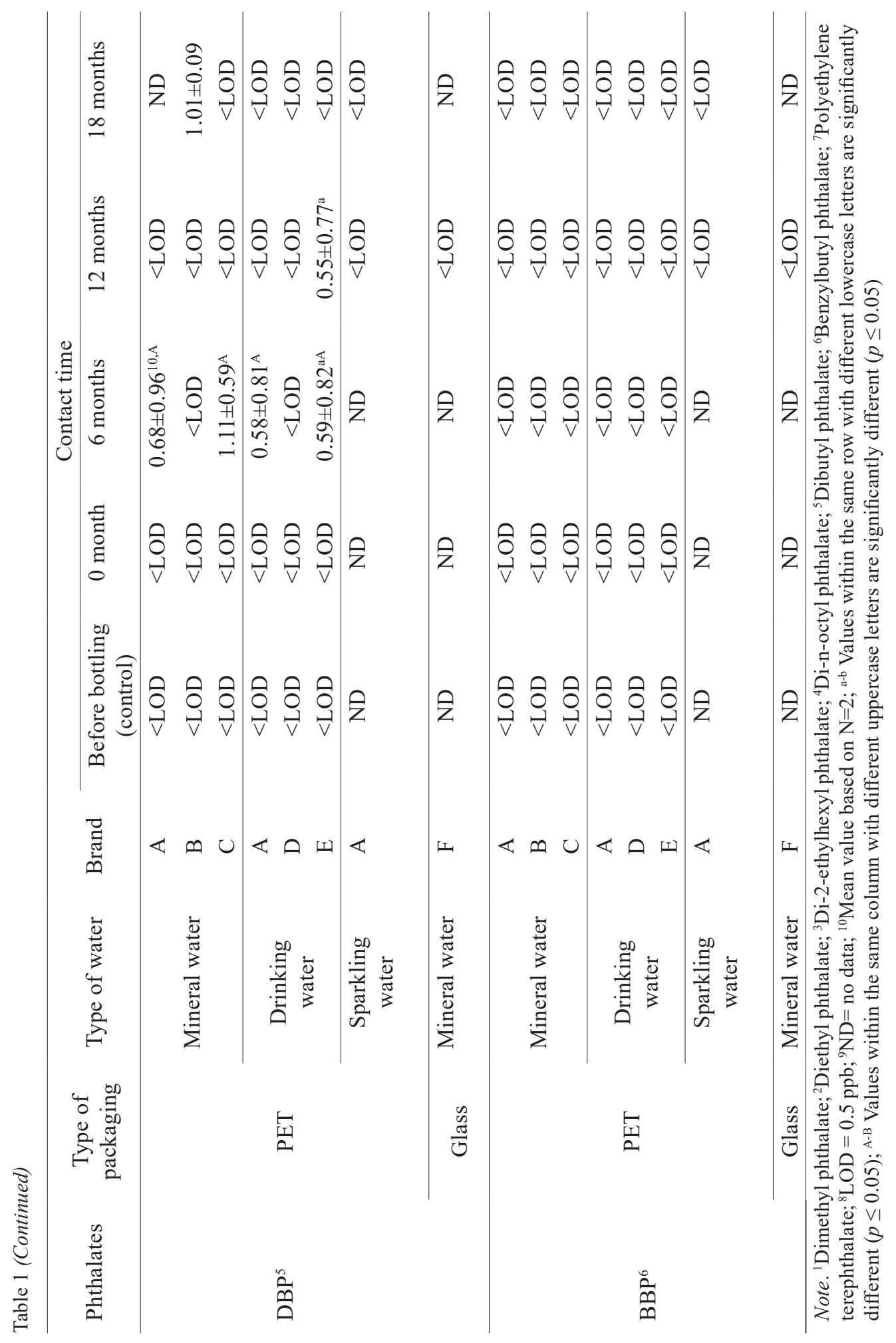


for non-carbonated and carbonated drinks and found that the rate of DBP migration was higher for non-carbonated than carbonated drinks (Bosnir et al., 2007; Keresztes et al., 2013). The present study, however, did see such an observation. The finding may be because the present study is observational, and samples for each contact time were collected from different production batches and already subjected to different handling practices, as explained above.

All types of phthalates, including DBP were not detected in the mineral water in glass bottles (brand F) in contrast to the above-mentioned DBP levels in mineral and drinking water in PET bottles. The findings are consistent with the findings of Montuori et al. (2008), who reported that the concentrations of phthalates were nearly 20 times higher, i.e., determined at $3.52 \mathrm{ng} /$ $\mathrm{mL}$ in mineral water samples in PET bottles compared to glass bottles $(0.19 \mathrm{ng} / \mathrm{mL})$. Besides, the United States Environmental Protection Agency regulates DEHP through the National Primary Drinking Water Regulations under the Safe Drinking Water Act. The maximum contaminant levels of DEHP in drinking water has been set at $6.0 \mathrm{ng} / \mathrm{mL}$ (United States Environmental Protection Agency [US EPA], 1991). Since the levels of all phthalates in this study were below the maximum limit set for DEHP, which is $6 \mathrm{ng} / \mathrm{mL}$, the bottled water that is commercially available on the market is considered as safe from phthalate contamination. However, it should be noted that there are no international guidelines for
DBP or other phthalates in drinking water except for DEHP (Al-Saleh et al., 2011).

\section{CONCLUSION}

The present study showed that DEHP, DMP, DEP, DnOP, and BBP were not detected in the bottled water samples collected at different contact times. DBP was detected in the PET-bottled drinking water samples (brand E) with 6 months and 12 months of contact times, although the difference was not significant. It appears that contact time does not significantly affect DBP levels. All types of phthalates, including DBP were not detected in the following samples: control (before bottling), freshly produced (0-month), sparkling water in PET-bottles, and mineral water in glass bottles. Phthalates in all samples did not exceed the maximum established limit of DEHP $(<6 \mathrm{ng} / \mathrm{mL})$. This study will serve as a reference for future researchers in determining the dietary exposure of phthalates from bottled water.

\section{ACKNOWLEDGMENTS}

The authors gratefully acknowledge the Food Safety and Quality Division, Ministry of Health Malaysia for the technical support and funding received, and the Higher Institution Centres of Excellence (HICOE) environment set by the Ministry of Education of Malaysia at Institute of Tropical Agriculture and Food Security, Universiti Putra Malaysia. 


\section{REFERENCES}

Al-Saleh, I., Shinwari, N., \& Alsabbaheen, A. (2011). Phthalates residues in plastic bottled waters. The Journal of Toxicological Sciences, 36(4), 469478. https://doi.org/10.2131/jts.36.469

Amiridou, D., \& Voutsa, D. (2011). Alkylphenols and phthalates in bottled waters. The Journal of Hazardous Materials, 185(1), 281-286. https:// doi.org/10.1016/j.jhazmat.2010.09.031

Bosnir, J., Puntaric, D., Galic, A., Skes, I., Dijanic, T., Klaric, M., Grgic, M., Curkovic, M., \& Smit, Z. (2007). Migration of phthalates from plastic containers into soft drinks and mineral water. Food Technology and Biotechnology, 45(1), 91-95.

Ceretti, E., Zani, C., Zerbini, I., Guzzella, L., Scaglia, M., Berna, V., Donato, F., Monarca, S., \& Feretti, D. (2010). Comparative assessment of genotoxicity of mineral water packed in polyethylene terephthalate (PET) and glass bottles. Water Research, 44(5), 1462-1470. https://doi.org/10.1016/j.watres.2009.10.030

Chang, L., Bi, P., Li, X., \& Wei, Y. (2015). Study of solvent sublation for concentration of trace phthalate esters in plastic beverage packaging and analysis by gas chromatography-mass spectrometry. Food Chemistry, 177, 127-133. https://doi.org/10.1016/j.foodchem.2015.01.013

Chong, K. W., Loke, C. F., \& Pang, M. (2011). Determination of six phthalates in polypropylene consumer products by sonication-assisted extraction/GC-MS methods. The Malaysian Journal of Analytical Sciences, 15(2), 167-117.

Gleick, P. (2010). The myth and reality of bottled water. https://www.researchgate.net/ publication/237588120_The_Myth_and_ Reality_of_Bottled_Water

Gomez-Hens, A., \& Aguilar-Caballos, M. P. (2003). Social and economic interest in the control of phthalic acid esters. Trends in Analytical Chemistry, 22(11), 847-857. https://doi.org/ https://doi.org/10.1016/S0165-9936(03)01201-9

Guart, A., Bono-Blay, F., Borrell, A., \& Lacorte, S. (2011). Migration of plasticizers phthalates, bisphenol A and alkylphenols from plastic containers and evaluation of risk. Food Additives and Contaminants: Part A: Chemistry, Analysis, Control, Exposure and Risk Assessment, 28(5), 676-685. https://doi.org/10.1080/19440049.20 11.555845

Hahladakis, J. N., Velis, C. A., Weber, R., Iacovidou, E., \& Purnell, P. (2018). An overview of chemical additives present in plastics: Migration, release, fate and environmental impact during their use, disposal and recycling. The Journal of Hazardous Materials, 344, 179-199. https://doi.org/https:// doi.org/10.1016/j.jhazmat.2017.10.014

Ibrahim, N., Osman, R., Abdullah, A., \& Saim, N. (2014). Determination of phthalate plasticisers in palm oil using online solid phase extractionliquid chromatography (SPE-LC). Journal of Chemistry, 2014, 682975. https://doi. org/10.1155/2014/682975

International Agency for Research on Cancer. (1982). IARC monographs on the evaluation of the carcinogenic risk of chemicals to humans, in some industrial chemicals and dyestuffs. IARC. https://monographs.iarc.fr/wp-content/ uploads/2018/06/mono29.pdf

Ito, Y., Kamijima, M., \& Nakajima, T. (2019). Di(2ethylhexyl) phthalate-induced toxicity and peroxisome proliferator-activated receptor alpha: A review. Environmental Health and Preventive Medicine, 24(1), 47. https://doi.org/10.1186/ s12199-019-0802-z

Jia, P., Xia, H., Tang, K., \& Zhou, Y. Q. (2018). Plasticizers derived from biomass resources: A short review. Polymers, 10(12), 1303. https:// doi.org/https://doi.org/10.3390/polym10121303 
Keresztes, S., Tatar, E., Cazegeny, Z., Zaray, G., \& Mihucz, V. G. (2013). Study on the leaching of phthalates from polyethylene terephthalate bottles into mineral water. Science of The Total Environment, 458-460, 451-458. https://doi.org/ https://doi.org/10.1016/j.scitotenv.2013.04.056

LaFleur, A. D., \& Schug, K. A. (2011). A review of separation methods for the determination of estrogens and plastics-derived estrogen mimics from aqueous systems. Analytica Chimica Acta, 696(1), 6-26. https://doi.org/https://doi. org/10.1016/j.aca.2011.03.054

Leivadara, S. V., Nikolaou, A. D., \& Lekkas, T. D. (2008). Determination of organic compounds in bottled waters. Food Chemistry, 108(1), 277286. https://doi.org/https://doi.org/10.1016/j. foodchem.2007.10.031

Montuori, P., Jover, E., Morgantini, M., Bayona, J. M., $\&$ Triassi, M. (2008). Assessing human exposure to phthalic acid and phthalate esters from mineral water stored in polyethylene terephthalate and glass bottles. Food Additives and Contaminants: Part A: Chemistry, Analysis, Control, Exposure and Risk Assessment, 25(4), 511-518. https://doi. org/10.1080/02652030701551800

Penalver, A., Pocurull, E., Borrull, F., \& Marce, R. M. (2001). Comparison of different fibers for the solid-phase microextraction of phthalate esters from water. Journal of Chromatography A, 922(1-2), 377-384. https://doi.org/10.1016/ s0021-9673(01)00920-7

Rahman, M., \& Brazel, C. S. (2004). The plasticizer market: An assessment of traditional plasticizers and research trends to meet new challenges. Progress in Polymer Science, 29(12), 1223-1248. https://doi.org/10.1016/j. progpolymsci.2004.10.001

Robertson, G. L. (2013). Food Packaging: Principles and practice (Vol. 3). Taylor \& Francis Inc.

Schmid, P., Kohler, M., Meierhofer, R., Luzi, S., $\&$ Wegelin, M. (2008). Does the reuse of PET bottles during solar water disinfection pose a health risk due to the migration of plasticisers and other chemicals into the water?. Water Research, 42(20), 5054-5060. https://doi. org/10.1016/j.watres.2008.09.025

Schreiber, A., Fu, F., Yang, O., Wan, E., Gu, L., \& LeBlanc, Y. (2011). Increasing selectivity and confidence in detection when analyzing phthalates by LC-MS/MS. http://sciex. com/Documents/brochures/Phthalates QTRAP5500\%20SelexION_3690411.pdf

Serodio, P., \& Nogueira, J. M. F. (2006). Considerations on ultra-trace analysis of phthalates in drinking water. Water Research, 40(13), 2572-2582. https://doi.org/https://doi.org/10.1016/j. watres.2006.05.002

Silano, V., Barat Baviera, J. M., Bolognesi, C., Chesson, A., Cocconcelli, P. S., Crebelli, R., Gott, D. M., Grob, K., Lampi, E., Mortensen, A., Riviere, G., Steffensen, I. L., Tlustos, C., Loveren, H. V., Vernis, L., Zorn, H., Cravedi, J. P., Fortes, C., Pocßas, M. F. T., ... Castle, L. (2019). Update of the risk assessment of di-butylphthalate (DBP), butyl-benzylphthalate (BBP), bis(2-ethylhexyl)phthalate (DEHP), di-isononylphthalate (DINP) and diisodecylphthalate (DIDP) for use in food contact materials. EFSA Journal, 17(12), e05838. https:// doi.org/10.2903/j.efsa.2019.5838

Sulentic, R. O., Dumitrascu, I., Deziel, N. C., \& Gurzau, A. E. (2018). Phthalate exposure from drinking water in Romanian adolescents. International Journal of Environmental Research and Public Health, 15(10), 2109. https:/doi. org/10.3390/ijerph15102109

United States Environmental Protection Agency. (1991). National primary drinking water regulations. US EPA. https://www.epa.gov/ ground-water-and-drinking-water/nationalprimary-drinking-water-regulations 